\title{
O papel das famílias no Programa Nacional de Fortalecimento dos Conselhos Escolares.
}

\author{
The role of families in the National Program for Strengthening \\ of School Councils
}

\section{El rol de las famílias en el Programa Nacional de Fortalecimiento de los Consejos Escolares.}

\author{
Adriana Grabner Corrêa ${ }^{1}$ \\ Letícia Veiga Casanova ${ }^{2}$ \\ Valéria Silva Ferreira ${ }^{3}$
}

\section{Resumo}

As relações escolas-famílias constituem-se a partir de diferentes saberes, interesses e estratégias, fruto das interações complexas entre diferentes atores e o governo brasileiro investiu nessa relação a partir da elaboração do Programa Nacional de Fortalecimento dos Conselhos Escolares. O Programa disponibiliza 12 cadernos que subsidiam oficinas e cursos ofertados aos membros dos Conselhos Escolares de cada instituição educativa. Esses documentos representam interesses, jogos de poder e sistemas que estabelecem formas sistemáticas dos discursos nos documentos da política. Neste texto, analisamos essas publicações com o intuito de identificar o papel das famílias e mapear as propostas de participação dos pais. Os resultados apontam que os cadernos enfatizam a participação da família em vários momentos de forma indefinida e responsabilizam os pais pelo sucesso na aprendizagem. De uma forma geral, a relação que se estabelece é assimétrica e os documentos oficiais legitimam a força da escola em anunciar e determinar como a família deve agir.

Palavras-chave: conselho escolar; família; participação.

\begin{abstract}
The relationships between schools and families are based on different knowledge, interests and strategies, resulting from the complex interactions among the actors of schools, families, society and State. The National Program for Strengthening of School Councils provides 12 books that subsidize workshops and courses offered by the Program and Secretariats of Education to School Councils. These documents represent interests, games of power, and

\footnotetext{
1 Formada em Psicologia pela Universidade do Vale do Itajaí - UNIVALI- Itajaí (SC), Brasil. Email: adrianagrabnercorrea@gmail.com

${ }^{2}$ Doutora em Educação pela Universidade do Vale do Itajaí - UNIVALI e pesquisadora do grupo de pesquisa Contextos da Educação da Criança na mesma Universidade - Itajaí (SC), Brasil. E-mail: leticia.casanova@univali.brＯrcid:https://orcid.org/0000-0002-7548-6565 - L Lattes: http://lattes.cnpq.br/3476597266431261

3 Doutora em Educação (Psicologia da Educação) pela Pontifícia Universidade Católica de São Paulo, é professora pesquisadora permanente do Programa Pós-Graduação em Educação da UNIVALI (Mestrado e Doutorado) e lidera o grupo de pesquisa Contextos da Educação da Criança. Coordena o Programa de PósGraduação em Educação, Mestrado e Doutorado da UNIVALI- Itajaí (SC), Brasil. E-mail: v.ferreira@univali.br Orcid: https://orcid.org/0000-0002-3990-7182 - Lattes: http://lattes.cnpq.br/2155129322801874
} 
systems that establish systematic forms of discourse in documents of policy. In this text, we analyze these publications in order to identify the role of families and map the proposals for parental participation. The results indicate that the books emphasize the participation of the family in several moments of indefinite form and hold the parents responsible for the success in learning. In general, the relationship established is asymmetric and the official documents legitimize the strength of the school in announcing and determining how the family should act.

Keywords - school council; family; participation.

\section{Resumen}

Las relaciones escuelas y familias se constituyen a partir de diferentes saberes, intereses y estrategias, fruto de las interacciones complejas entre diferentes actores, y el gobierno brasileño invirtió en esa relación a partir de la elaboración del Programa Nacional de Fortalecimiento de los Consejos Escolares. El Programa dispone de 12 cuadernos que subsidian oficinas y cursos ofertados a los miembros de los Consejos Escolares de cada institución educativa. Esos documentos representan intereses, juegos de poder y sistemas que establecen formas sistemáticas de los discursos en los documentos de la política. En el texto, analizamos esas publicaciones con el intuito de identificar el papel de las familias y mapear las propuestas de participación de los padres. Los resultados apuntan que los cuadernos destacan la participación de la familia en varios momentos de forma indefinida y responsabilizan a los padres por el éxito en el aprendizaje. De una forma general, la relación que se establece es asimétrica y los documentos oficiales legitiman la fuerza de la escuela en anunciar y determinar como la familia debe actuar.

Palabras clave - consejo escolar; família; participación

\section{Relações escolas-famílias e os documentos da política de Educação Básica}

As relações escolas-famílias constituem-se a partir de diferentes saberes, discursos, interesses e estratégias ao longo da história, fruto das interações complexas e interesses que se estabelecem entre os atores das escolas, das famílias, da sociedade e do Estado. Essas relações nascem com a escolarização das crianças, com o processo formal de educação oferecido pelas instituições de ensino, no contato direto ou indireto dessas duas instituições responsáveis pela educação das crianças, ou seja, família e escola. Dessa forma, desde que as crianças começaram a frequentar a escola, essas relações foram estabelecendo-se e construindo-se. Silva (2003) enfatiza que as relações escolas-famílias têm a idade da instituição escolar e sempre houve algum tipo de relação entre elas, “[...] ora mais direta, mais explícita, mais próxima, mais formal, mais harmoniosa; ora mais indireta, mais implícita, mais distante, mais informal, mais tensa" (SILVA, 2003, p. 29).

Revista Devir Educação, Lavras, vol.5, n2., p.207-223 jul./dez., 2021. 
Essas ideias e esses discursos vão fabricando os sujeitos dessa relação. Essa sujeição valoriza relações mais próximas entre escolas e famílias e ganha destaque na contemporaneidade. Como definem Resende e Silva (2016), as relações escolas-famílias constituem um tema com importância e visibilidade crescentes na sociedade atual, "[...] conquistando espaços nos meios de comunicação, nas políticas públicas, nos projetos pedagógicos das escolas, na pesquisa científica sobre educação" (RESENDE; SILVA, 2016, p. 30). Para Silva, (2003, p. 27, grifo do autor), as relações escolas-famílias estão na moda e “[...] mesmo para quem não segue de perto as coisas da educação torna-se relativamente fácil 'tropeçar' regularmente em notícias sobre o tema".

Há um movimento, no Brasil, de recomendações de ações às escolas e às famílias nos documentos da política para a Educação Básica, assim como também é visível em várias partes do mundo ocidental. Nogueira (2005) traz alguns exemplos como: nos Estados Unidos, em 1994, o estabelecimento da colaboração família-escola na oitava meta da educação nacional; na Inglaterra, nos anos de 1990, a criação de um "contrato casa-escola", no qual os pais se comprometiam a assumir a responsabilidade no plano da assiduidade, da disciplina, da realização dos deveres dos seus filhos; na França, em 1998, o lançamento de uma campanha nacional pela parceria família-escola, sendo uma das ações a "semana dos pais na escola".

No Brasil, não é diferente. Os documentos da política para a Educação Básica apontam para ações que incentivam essa relação como: a Lei de Diretrizes e Bases da Educação (BRASIL, 1996), a qual define que os estabelecimentos de ensino terão a incumbência de articular-se com as famílias e a comunidade. O Programa Nacional de Fortalecimento dos Conselhos Escolares (BRASIL, 2004a), que visa garantir a participação da comunidade escolar e local na gestão das escolas e na melhoria da qualidade do ensino.

Esses documentos representam interesses, jogos de forças, poderes e os sistemas que estabelecem as formas sistemáticas, últimas dos discursos nos documentos da política. Além disso, documentos da política representam a síntese dessas disputas e definem o lugar que se quer chegar, o tipo de relação entre escolas e famílias deseja-se e qual o papel delineado para as famílias.

\section{As relações escolas-famílias e o Programa Nacional de Fortalecimento dos Conselhos}

\section{Escolares}

Revista Devir Educação, Lavras, vol.5, n2., p.207-223 jul./dez., 2021. 
No Programa Nacional de Fortalecimento dos Conselhos Escolares, podemos observar algumas dessas disputas. Esse Programa foi criado em 17 de setembro de 2004, com a Portaria Ministerial $n^{\circ}$ 2.896/2004, por meio da Coordenação-Geral da Articulação e Fortalecimento Institucional dos Sistemas de Ensino (CAFISE) e do Departamento de Articulação e Desenvolvimento dos Sistemas de Ensino (DASE). O Programa conta com a participação de organismos nacionais e internacionais em um Grupo de Trabalho constituído para discutir, analisar e propor medidas para sua implementação (BRASIL, 2004a). Fazem parte do Grupo de Trabalho: Conselho Nacional de Secretários de Educação (Consed), União Nacional dos Dirigentes Municipais de Educação (Undime), Confederação Nacional dos Trabalhadores em Educação (CNTE), Fundo das Nações Unidas para a Infância (Unicef), Organização das Nações Unidas para a Educação, a Ciência e a Cultura (Unesco), Programa das Nações Unidas para o Desenvolvimento (Pnud).

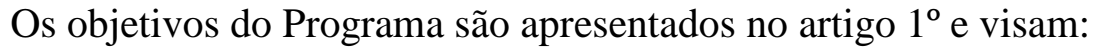

I - ampliar a participação das comunidades escolar e local na gestão administrativa, financeira e pedagógica das escolas públicas;

II - apoiar a implantação e o fortalecimento de Conselhos Escolares;

III - instituir políticas de indução para a implantação de Conselhos Escolares;

IV - promover, em parceria com os sistemas de ensino, a capacitação de conselheiros escolares, utilizando inclusive metodologias de educação à distância;

V - estimular a integração entre os Conselhos Escolares;

VI - apoiar os Conselhos Escolares na construção coletiva de um projeto educacional no âmbito da escola, em consonância com o processo de democratização da sociedade;

VII - promover a cultura do monitoramento e avaliação no âmbito das escolas para a garantia da qualidade da educação. (BRASIL, 2004a, p. 7).

Podemos verificar estratégias de ampliar a participação, instituir, apoiar e capacitar os Conselhos Escolares, promover a cultura do monitoramento e da avaliação, garantindo a qualidade da educação. Observamos, dessa maneira, criação de estratégias, procedimentos de condutas, estabelecimento de mecanismos reguladores (FOUCAULT, 2010, 2015) dos profissionais das escolas e das famílias.

O portal do Ministério da Educação ${ }^{4}$ explica que o objetivo do Programa é fomentar a implantação dos conselhos escolares, por meio da elaboração de materiais didáticos específicos e formação continuada, tanto presencial quanto a distância a técnicos das

\footnotetext{
4 Disponível em: <http://portal.mec.gov.br/programa-nacional-de-fortalecimento-dos-conselhos-escolares〉.
} Acesso em: 18 dez. 2015.

Revista Devir Educação, Lavras, vol.5, n2., p.207-223 jul./dez., 2021. 
Secretarias Estaduais e Municipais de Educação, assim como para os conselheiros escolares. Dessa forma, a elaboração do material pedagógico, a formação continuada presencial e a formação continuada a distância são os três pilares que estruturam esse Programa.

O material didático é composto por 12 cadernos. Os 5 primeiros foram elaborados no ano de 2004, são eles: Caderno 1 - Conselhos Escolares: Democratização da escola e construção da cidadania; Caderno 2 - Conselho Escolar e a aprendizagem na escola; Caderno 3 - Conselho Escolar e o respeito e a valorização do saber e da cultura do estudante e da comunidade; Caderno 4 - Conselho Escolar e o aproveitamento significativo do tempo pedagógico; Caderno 5 - Conselho Escolar, gestão democrática da educação e escolha do diretor.

Em 2006, foram lançados mais 5 cadernos: Caderno 6 - Conselho Escolar como espaço de formação humana: círculo de cultura e qualidade da educação; Caderno 7 Conselho Escolar e o financiamento da educação no Brasil; Caderno 8 - Conselho Escolar e a valorização dos trabalhadores em educação; Caderno 9 - Conselho Escolar e a educação do campo; Caderno 10 - Conselho Escolar e a relação entre a escola e o desenvolvimento com igualdade social. Em 2008 e 2009, foram lançados os últimos cadernos: Caderno 11 Conselho Escolar e Direitos Humanos; e Caderno 12 - Conselho Escolar e sua organização em fórum.

Os Cadernos tratam de forma prescritiva sobre o significado do Conselho na gestão da escola. Eles definem sua função, descrevem as legislações que o sustentam, seu modo de funcionamento e atuação, como o acompanhamento da prática educativa e do tempo pedagógico. Sobre a definição da função do Conselho Escolar, o site do Ministério da Educação ${ }^{5}$ descreve que:

Aos conselhos escolares cabe deliberar sobre as normas internas e o funcionamento da escola, além de participar da elaboração do Projeto Político-Pedagógico; analisar as questões encaminhadas pelos diversos segmentos da escola, propondo sugestões; acompanhar a execução das ações pedagógicas, administrativas e financeiras da escola e mobilizar a comunidade escolar e local para a participação em atividades em prol da melhoria da qualidade da educação, como prevê a legislação. (BRASIL, 2016, s/p).

Os cadernos tratam do Conselho Escolar como exercício de poder pela participação e retratam, no Caderno Instrucional: uma estratégia de gestão democrática da escola pública, que:

5 Disponível em: <http://portal.mec.gov.br/programa-nacional-de-fortalecimento-dos-conselhosescolares>. Acesso em: 22 dez. 2015.

Revista Devir Educação, Lavras, vol.5, n2., p.207-223 jul./dez., 2021. 
Os conselhos escolares na educação básica, concebidos pela LDB como uma das estratégias de gestão democrática da escola pública, tem como pressuposto o exercício do poder, pela participação, das comunidades escolar e local [...]. O conselho existe para dizer aos dirigentes o que a comunidade quer da escola e, no âmbito de sua competência, o que deve ser feito. (BRASIL, 2004b, p. 36-37).

Há, nesses cadernos, estratégias que orientam para a participação, a discussão, a construção coletiva do que a comunidade quer da escola e o que deve ser feito. Mas perguntase: como é definido o papel das famílias nos cadernos do Programa Nacional de Fortalecimento dos Conselhos Escolares? Quais são as propostas de participação?

Verificamos que esse Programa fortalece o discurso da participação e da gestão democrática marcada desde a Constituição Federal de 1988. Constituição esta que garantiu na legislação a busca pelos movimentos sociais ao direito à participação e o princípio da gestão democrática na educação (BRASIL, 1988).

Com a promulgação da Constituição Federal em 1988, definiu-se, entre outras questões, o princípio da gestão democrática para educação. É importante esclarecer, porém, que as leis são as formas terminais do poder (FOUCAULT, 2010) e, dessa maneira, antes da definição do que seria a gestão democrática na Constituição, houve disputas, tensões, jogos de forças ao definir tal princípio. Como esclarece Foucault (2015, p. 138), “[...] cada luta se desenvolve em torno de um foco particular".

Adrião e Camargo (2002) apontam a existência de duas principais posições, responsáveis pelos embates ocorridos nas comissões encarregadas da discussão desse processo:

O primeiro setor refere-se ao grupo identificado com as posições do Fórum Nacional em Defesa da Escola Pública constituído por entidades de caráter nacional cujo posicionamento, no tocante à gestão da educação e da escola, refletia a defesa do direito à população usuária (pais, alunos e comunidade local) de participar da definição das políticas educacionais às quais estariam sujeitos [...]. O segundo setor, ligado aos interesses privados do campo educacional e composto, tanto por representantes do chamado empresariado educacional, quanto por representantes ligados às escolas confessionais, contrapunha-se a tal formulação. Aqui, o grau 'aceitável' de participação resumia-se à possibilidade de famílias e educadores colaborarem com direções e/ou mantenedoras dos estabelecimentos de ensino (ADRIÃO; CAMARGO, 2002, p. 73, grifo dos autores).

Os embates e as disputas estabeleceram-se no sentido de garantir na lei a ideia de indução para as modificações das práticas sociais. O embate desse momento resultou na 
aprovação da seguinte redação: "Artigo 206 - O ensino será ministrado com base nos seguintes princípios: [...]; VI - gestão democrática do ensino público, na forma da lei” (BRASIL, 1988, p. 137-138).

Adrião e Camargo (2002) relatam que foi acrescentado o adjetivo público à palavra ensino e, dessa forma, excluiu-se a aplicação da gestão democrática ao ensino privado. Com a expressão na forma da lei, exige-se uma legislação complementar para que seja executável. Essa redação não foi somente uma conquista por parte dos segmentos comprometidos com a democratização da gestão da educação, mas também “[...] representou uma conquista parcial, na medida em que teve sua abrangência limitada e sua operacionalização delegada a regulamentações futuras" (ADRIÃO; CAMARGO, 2002, p. 74).

Notamos a ideia de gestão democrática na participação de representantes na escola, do aumento da participação dos pais. Tudo isso construído nas relações entre movimentos sociais e Estado, embates e ajustes, visando estabelecer condutas de escolas e famílias. Após a Constituição de 1988, outras leis, outros decretos, documentos, programas, materiais de orientações foram construídos. Outros embates, outras identidades, outros conceitos e outras conduções foram estabelecidas para a relação entre escolas e famílias, assim como para a gestão das escolas e dos Conselhos Escolares. Diante disso, consideramos importante investigar o papel da família delineada no Programa Nacional de Fortalecimento dos Conselhos Escolares.

Cury (2008, p. 199) relata que a Constituição Federal incorporou, em seu texto, “[...] os clamores dos educadores que, exigindo a democratização da sociedade e da escola pública brasileiras, buscaram traduzi-los em preceitos legais" (CURY, 2008, p. 199). E a lógica democrática, reivindicada pelos movimentos sociais e aferida na constituinte, "[...] refletia a defesa do direito à população usuária (pais, alunos e comunidade local) de participar da definição de políticas educacionais" (ADRIÃO; CAMARGO, 2002, p. 72). Como define Paro (2006), devemos entender a democratização não apenas como escola para todos, como universalização da educação, mas precisamos compreendê-la no sentido de:

[...] democratização das relações que envolvem a organização e o funcionamento efetivo da instituição escola. Trata-se, portanto, das medidas que vêm sendo tomadas com a finalidade de promover a partilha do poder entre dirigentes, professores, pais, funcionários, e de facilitar a participação de todos os envolvidos nas tomadas de decisões relativas ao exercício das funções da escola com vistas à realização de suas finalidades. (PARO, 2006, p. 1).

Revista Devir Educação, Lavras, vol.5, n2., p.207-223 jul./dez., 2021. 
A Lei de Diretrizes e Bases 9.394/96 também enaltece esse discurso. Observamos que, nos artigos $3^{\circ}$ e 14 da LDB 9.394/96, a gestão democrática é um dos princípios do ensino público. A Lei salienta que os sistemas de ensino definirão as normas da gestão democrática conforme os princípios de participação dos profissionais da educação na construção do projeto político pedagógico da escola e da participação das comunidades escolar e local em conselhos escolares (BRASIL, 1996).

Paro (2002, p. 80) esclarece que o artigo $3^{\circ}$ repete a fórmula da Constituição Federal e o artigo 14 "[...] faz supor, que, em termos de legislação federal, esta lei esgota o assunto", pois apenas define a participação das famílias nos órgãos de gestão, como o conselho escolar. Muranaka e Minto (2001, p. 63) também concordam que, apesar de os conselhos escolares serem organismos reivindicados pelos setores organizados da sociedade civil no período de democratização do país, “[...] a redação do artigo 14 da LDB posterga a definição dos espaços de participação $[\ldots . .$. ".

A partir da LDB 9.394/96 outros documentos foram elaborados para a política de Educação Básica, e alguns deles definem ideias e conduzem condutas para as relações entre escolas e famílias, como os cadernos do Programa Nacional de Fortalecimento dos Conselhos Escolares (BRASIL, 2004a). Dessa forma, objetivamos mapear as propostas de participação das famílias nos documentos do Programa Nacional de Fortalecimento dos Conselhos Escolares e, em especial, os tipos de ações indicados por esses documentos. Identificamos o papel das famílias nessas ações e analisamos as concepções de participação das famílias abordadas nesses documentos.

Assim sendo, buscamos compreender o sentido e o significado das intencionalidades das políticas educacionais. Para Ghedin e Franco (2008, p. 72), “[...] a pesquisa em educação possui uma particularidade incomparável com as outras ciências, especialmente porque os objetos das ciências da educação e seus métodos implicam processos diferenciados de acesso ao real". Como caminho metodológico, utilizamos a "análise documental" definida por Bell (1997) quando os documentos são o alvo do estudo. Para Flores (1994), a análise documental consiste na identificação de unidades de significado em um texto e na investigação das relações entre elas e o todo. O autor ainda complementa que esse tipo de análise é constituído por dois momentos: recolha e análise dos documentos.

Para o momento de recolha, realizamos uma busca no site do Ministério da Educação. Os documentos, 12 cadernos do Programa Nacional de Fortalecimento dos Conselhos 
Escolares, foram salvos em PDF. A escolha por esse aplicativo baseou-se nas possibilidades que a ferramenta "localizador" oferece: mapear os descritores em todo o texto. Para o mapeamento e o processo analítico, utilizamos os descritores: pais e famílias, no singular e no plural. A escolha deu-se por acreditarmos que esses termos nos dão acesso aos extratos dos documentos nos quais encontramos a discussão acerca do objeto pesquisado. Outro fator importante é que os descritores, ao serem contabilizados manualmente, permitem ao pesquisador observar os contextos em que eles aparecem no documento. Assim, é possível identificar se "famílias" e ou "pais" estão citados nesses documentos e permite analisar qual o lugar definido para eles, assunto que abordamos a seguir.

\section{O lugar das famílias no Programa Nacional de Fortalecimento dos Conselhos Escolares}

Entendemos que a família tem lugar de destaque na escolarização dos seus filhos e são as escolas que cultivam a parceria com elas. Acreditamos que uma relação família-escola se pauta no diálogo e na escuta atenta e sensível. Essa relação é permeada de complexidade e de tensão, por conta das diferenças entre a cultura escolar e as diversas culturas das famílias (LAHIRE, 1997). Compreendemos, também, que os documentos das políticas, como os cadernos do Programa Nacional de Fortalecimento dos Conselhos Escolares, são pensados e elaborados a partir de uma rede de influências que estão atravessadas de embates, interesses, jogos de forças para marcar um modo específico de participação das famílias nos Conselhos Escolares.

Um desses modos é descrito pelo discurso da gestão democrática e pela participação, mas observamos nos dados que esses modos não estão definidos claramente: O que seria participar? Como famílias podem participar? O que seria participar de uma gestão democrática?

O caderno 2, Conselho Escolar e aprendizagem na escola, por exemplo, defende que “[...] o papel do Conselho Escolar é o de ser o órgão consultivo, deliberativo e de mobilização mais importante do processo de gestão democrática" (BRASIL, 2004c, p. 20). Já o caderno 5, Conselho Escolar, gestão democrática e escolha do diretor, esclarece que é necessário um amplo trabalho de mobilização e conscientização “[...] para que estes [todos os envolvidos dirigentes escolares, professores, demais funcionários, estudantes e pais de estudantes] 


\section{OO DEVIR EDUCAÇÃO}

ISSN: 2526-849X

percebam a importância de participar da elaboração e da construção cotidianas dos projetos da escola" (BRASIL, 2004d, p. 20).

O princípio da gestão democrática preconiza o compartilhamento do poder na tomada de decisões dos processos educativos, tanto nas questões pedagógicas, financeiras quanto nas administrativas. Para tanto, é necessário a condição de não hierarquia, de partilha, de facilitar a participação de todos os envolvidos como dirigentes, professores, pais e funcionários (PARO, 2006). Isso seria para uma construção coletiva da educação mais macro e, sobretudo, para a construção dos contextos micro e locais de educação.

Diante desse cenário idealizado, há contextos reais das traduções dessas políticas. As intenções das políticas podem ganhar novos sentidos na prática, porém, segundo Ball (2014), há dispositivos que colaboram para a criação de novos discursos e projetam novas realidades, para os quais devemos ficar atentos. Neste artigo, apresentamos o contexto documental do Programa Nacional de Fortalecimento dos Conselhos Escolares na perspectiva das novas formas de sujeição e de esquemas de conhecimento que aparecem a partir dos dispositivos didáticos do programa em questão (FOUCAULT, 2010).

Ball (2014) fala-nos da performatividade para análise da escrita de documentos. O autor diz que esse conceito vai além de uma avaliação de sistemas de gestão de desempenho. Para o autor, incide no entendimento do que ele faz na subjetividade das pessoas, induzindoas a tornarem-se mais efetivas, sentirem-se culpadas ou inadequadas no que fazem. Como define Ball (2010, p. 38, grifo do autor), a performatividade é “[...] uma tecnologia, uma cultura e um modo de regulação, e mesmo, tal como define Lyotard, um sistema de 'terror', sistema que implica julgamento, comparação e exposição, tomados respectivamente como formas de controle, de atrito e de mudança”"

Aqui, especificamente, analisamos os 12 cadernos do Programa Nacional de Fortalecimento dos Conselhos Escolares e as ações previstas para as famílias, a sua performance esperada nesses documentos. No Quadro 1, que segue, apresentamos as ações e começamos a identificar que o papel das famílias é de partícipe, mas os próprios cadernos não definem como são as ações de participação, de que forma as famílias podem participar.

Quadro 1 - As famílias no Conselho Escolar e as ações de participação

\section{Cadernos $\quad$ Ações previstas}

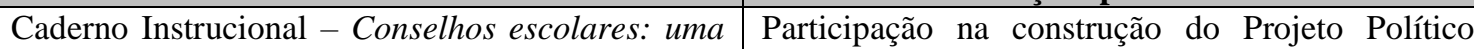
estratégia de gestão democrática da educação Pedagógico (PPP); participação para conhecer os pública estudantes; atuação da família e seus respectivos 


\begin{tabular}{|c|c|}
\hline & papéis. \\
\hline $\begin{array}{l}\text { Caderno 1- Conselhos escolares: democratização } \\
\text { da escola e construção da cidadania }\end{array}$ & $\begin{array}{l}\text { Partícipes da prática educativa; educadores; } \\
\text { divisão de responsabilidade pela aprendizagem } \\
\text { escolar. }\end{array}$ \\
\hline $\begin{array}{l}\text { Caderno } 2 \text { - Conselho Escolar e a aprendizagem } \\
\text { na escola }\end{array}$ & $\begin{array}{l}\text { Educação familiar; família como uma entidade } \\
\text { participante da comunidade. }\end{array}$ \\
\hline $\begin{array}{l}\text { Caderno } 3 \text { - Conselho escolar e o respeito e a } \\
\text { valorização do saber e da cultura do estudante e } \\
\text { da comunidade }\end{array}$ & $\begin{array}{l}\text { Família como participante da organização escolar, } \\
\text { em busca de atender o direito dos estudantes por } \\
\text { educação de qualidade; família como "recebedora" } \\
\text { de informação sobre possibilidades ofertadas aos } \\
\text { estudantes. }\end{array}$ \\
\hline $\begin{array}{l}\text { Caderno } 4 \text { - Conselho escolar e o aproveitamento } \\
\text { significativo do tempo pedagógico }\end{array}$ & $\begin{array}{l}\text { Família com integrante da escola; atores sociais; } \\
\text { participação cotidiana; reunião mensal para } \\
\text { discussão de temas diversos ligados à educação; } \\
\text { participação na associação de pais; decisões } \\
\text { partilhadas (calendário, eventos, avaliação } \\
\text { educacional, planejamento escolar). }\end{array}$ \\
\hline $\begin{array}{l}\text { Caderno } 5 \text { - Conselho escolar, gestão democrática } \\
\text { e escolha do diretor }\end{array}$ & $\begin{array}{l}\text { Dever de educar; contribuem na formação, mas } \\
\text { não respondem pela formação na educação básica } \\
\text { necessária nos tempos atuais; problemas: falta de } \\
\text { participação, de consciência da importância do } \\
\text { processo educativo; envolvimento nos processos } \\
\text { de avaliação e reprogramação das ações. }\end{array}$ \\
\hline $\begin{array}{l}\text { Caderno } 6 \text { - Conselho escolar como espaço de } \\
\text { formação humana: círculo de cultura e qualidade } \\
\text { da educação }\end{array}$ & $\begin{array}{l}\text { Dever de tomar as providências para a matrícula; } \\
\text { conhecer a legislação atual; discussão da } \\
\text { legislação e recursos financeiros; associações de } \\
\text { pais para recebimento do PDDE. }\end{array}$ \\
\hline $\begin{array}{l}\text { Caderno } 7 \text { - Conselho escolar e o financiamento } \\
\text { da educação no Brasil }\end{array}$ & Participar do planejamento participativo. \\
\hline $\begin{array}{l}\text { Caderno } 8 \text { - Conselho escolar e a valorização dos } \\
\text { trabalhadores em educação }\end{array}$ & $\begin{array}{l}\text { Valorizar os trabalhadores da educação básica; } \\
\text { construir uma escola cidadã. }\end{array}$ \\
\hline $\begin{array}{l}\text { Caderno } 9 \text { - Conselho escolar e a educação do } \\
\text { campo }\end{array}$ & $\begin{array}{l}\text { Participar da associação de pais; famílias são } \\
\text { atores sociais; participar não é cumprir tarefas } \\
\text { determinadas pela escola; Escola de campo: ciclo } \\
\text { de pais e mestres (ensinar técnicas de cultivo e } \\
\text { preparo de solo ou contribuir com a merenda } \\
\text { escolar). }\end{array}$ \\
\hline $\begin{array}{l}\text { Caderno } 10 \text { - Conselho Escolar e a relação entre } \\
\text { a escola e o desenvolvimento com igualdade social }\end{array}$ & $\begin{array}{l}\text { Colaboração; zelar pela frequência escolar; manter } \\
\text { as famílias atualizadas sobre o desempenho } \\
\text { escolar; atendimento a famílias em situação de } \\
\text { pobreza. }\end{array}$ \\
\hline $\begin{array}{l}\text { Caderno } 11-\text { Conselho Escolar e direitos } \\
\text { humanos }\end{array}$ & $\begin{array}{l}\text { São atores sociais e sujeitos de direitos - a exercer } \\
\text { cidadania ativa no cotidiano da escola; } \\
\text { responsabilidade de manutenção escolar; formação } \\
\text { de seres humanos. }\end{array}$ \\
\hline $\begin{array}{l}\text { Caderno } 12 \text { - Conselho Escolar e sua organização } \\
\text { em fórum }\end{array}$ & $\begin{array}{l}\text { Participação da assembleia geral; participação nos } \\
\text { fóruns; atuação junto à comunidade; } \\
\text { responsabilidade de conduzir a luta por melhoria }\end{array}$ \\
\hline
\end{tabular}




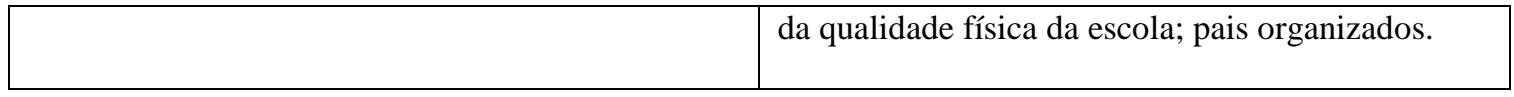

Fonte: Elaborado pelas autoras com base nos dados dos cadernos do Programa Nacional de Fortalecimento dos Conselhos Escolares.

Os cadernos enfatizam a "participação da família" em vários momentos de forma não muito clara, como: participar da associação de pais, participar de assembleia geral, participar das decisões, participar da construção do Projeto Político Pedagógico (PPP). O que se observa é um movimento de conduzir a participação das famílias em um formato em que a escola define em que ações as famílias devem participar. Não é uma relação construída coletivamente, cuja participação é negociada e pensada em conjunto.

Observamos, aqui, um aspecto que define o papel das famílias não como colaboradoras no pensar coletivamente a educação e a participação, mas as famílias tornam-se agentes passivos, executando o que foi determinado pela escola. Há, dessa maneira, um lugar reservado às famílias para execução de algo estabelecido e não um lugar de encontro, discussão, diálogo, construção coletiva do que se pretende. Ferrarotto e Malavasi (2016) também reconhecem que os documentos da política colocam as famílias apenas como complementares às ações da escola.

O discurso é de participação, mas, de uma forma geral, a relação que se estabelece é assimétrica, ou seja, os documentos oficiais legitimando a força da escola em anunciar e determinar como a família deve agir. O que se percebe é uma participação unilateral. Há uma tentativa de controle velado, no qual se reúnem técnicas de vigilância calculada que deveria ser exercida pelos conselhos escolares, mais sobre os resultados do que os processos. A família entra como coadjuvante desse processo para legitimar as ações previstas para esse conselho.

Os documentos citam que o papel da família é de participação e apontam que devem colaborar com o Projeto Político Pedagógico, com a organização escolar ou associação de pais, por exemplo, o que de fato não sabemos se isso acontece. Contudo, o que podemos concluir com os dados é que a participação não é posta como algo negociado, construído coletivamente, um processo em espiral aberto (BONDIOLI; SAVIO, 2013).

Os documentos também enaltecem a responsabilidade de as famílias conduzirem a luta pela qualidade da educação. Na apresentação dos 12 cadernos do Programa, destaca-se que “[...] este é um importante passo para garantir a efetiva participação das comunidades escolar e local na gestão das escolas, contribuindo, então, para a melhoria da qualidade social da 
educação ofertada para todos" (BRASIL, 2004e, p. 11). Entretanto, os cadernos não indicam os caminhos e as ferramentas para tal luta e nem abrem o diálogo para busca dessa problemática e para o consenso sobre o que se entende por qualidade.

É importante reconhecermos que a qualidade se traduz como um conceito relativo e baseado em valores (MOSS, 2002). Esse processo de definir qualidade oferece oportunidades para compartilhar, discutir e entender valores, ideias, conhecimentos e vivências. Moss (2002) ressalta que esse processo deve ser participativo e democrático, envolvendo grupos diferentes, que incluem alunos, famílias e profissionais de forma dinâmica, contínua e que requer sempre revisões. Dourado e Oliveira (2009) também apontam que:

A discussão acerca da qualidade da educação remete à definição do que se entende por educação. Para alguns, ela se restringe às diferentes etapas de escolarização que se apresentam de modo sistemático por meio do sistema escolar. Para outros, a educação deve ser entendida como espaço múltiplo, que compreende diferentes atores, espaços e dinâmicas formativas, efetivado por meio de processos sistemáticos e assistemáticos. (DOURADO; OLIVEIRA, 2009, p. 203).

A qualidade então não se reduz a questões puramente técnicas e gerenciais. Nesse contexto, para Campos e Haddad:

[...] a obtenção de consensos nessa área será sempre provisória, pois a qualidade é um conceito socialmente construído. Depende do contexto, fundamenta-se em direitos, necessidades, demandas, conhecimentos e possibilidades que também são determinados historicamente, sendo, portanto, resultado de processos que, em uma sociedade democrática, supõem constantes negociações e contínuas revisões. (CAMPOS; HADDAD, 2005, p. 112).

Reiteramos que a qualidade é um conceito socialmente construído, dependente do contexto em que a sociedade está inserida e, em uma perspectiva democrática, deveria ser construída coletivamente a partir das relações entre escolas, famílias e comunidade, com um pleno respeito à cultura local dos alunos.

Precisamos atentar que, para além de todos os documentos mobilizarem e incentivarem a participação das famílias, a maioria induz para ações que se fundamentam em valores que transformam as relações plurais, complexas, de participação, de negociação, de reflexão e de construção coletiva em uma relação simplista, que concentra os sujeitos no monitoramento e no gerenciamento de metas já estabelecidas. 


\section{Considerações finais}

Neste texto, discutimos que as relações escolas-famílias se constituem a partir de diferentes saberes, discursos, interesses e estratégias ao longo da história, fruto das interações complexas que se estabelecem entre os atores das escolas, das famílias, da sociedade e do Estado.

Observamos que tanto no Brasil quanto no mundo há um movimento nos documentos das políticas educacionais que valoriza as relações escolas-famílias mais próximas e incentiva para que pais e mães participem da vida escolar dos seus filhos. Essas ideias e esses discursos definem o lugar das famílias, das escolas e fabricam os sujeitos dessa relação.

Esses documentos representam interesses, jogos de forças, poderes e os sistemas que estabelecem as formas sistemáticas, últimas dos discursos nos documentos da política. Além disso, documentos da política representam a síntese dessas disputas e definem onde se quer chegar, que tipo de relação entre escolas e famílias deseja-se e qual o papel delineado para as famílias. Esses documentos são leis, decretos, programas, materiais de orientação e divulgação que são elaborados a partir de elementos comuns. Esses elementos sustentam-se a partir de valores e interesses e contribuem para a construção das ideias sobre as relações entre escolas e famílias, criam discursos, geram efeitos e sentidos nas pessoas, definem as opções disponíveis e o lugar social dos sujeitos na relação com a escola.

A partir da LDB 9.394/96, outros documentos foram elaborados para a política de Educação Básica e, alguns deles, definem ideias e conduzem condutas para as relações entre escolas e famílias, como o Programa Nacional de Fortalecimento dos Conselhos Escolares (BRASIL, 2004a). O Programa visa garantir a participação da comunidade escolar e local na gestão das escolas e na melhoria da qualidade do ensino e define o lugar das famílias na relação com a escola.

Por mais que os cadernos do Programa incentivem para a participação das famílias e fortaleçam o discurso de uma gestão democrática em busca da educação de qualidade, esses documentos estipulam um lugar secundário às famílias. Não há o movimento de criação de espaços de discussões, reflexões e construções coletivas sobre o que é qualidade, participação na educação.

Concordamos com Ferraroto e Malavasi (2016) quando ressaltam que, nos documentos da política, a relação entre família-escola é apresentada de forma simplista e 


\section{OD DEVIR EDUCAÇÃO \\ ISSN: 2526-849X}

reducionista. Para as autoras, essa relação teria como principal objetivo a formação integral das crianças e não necessita apontar culpados ou estabelecer funções criando um clima de rivalidades e individualidades. Dessa forma, ressaltamos a indicação de Silva (2003) de que a família tem responsabilidades individuais, mas, na escola, as suas ações devem ser coletivas para construção de consensos e decisões conjuntas.

Como explanam Saraceno e Naldini (2003), a família é objeto de regulação do Estado, seja direta ou indiretamente e revelam que "[...] a intervenção do Estado na família data do nascimento do próprio Estado moderno" (SARACENO; NALDINI, 2003, p. 299). As autoras reforçam que o Estado determina padrões, distribui recursos, atribui direitos e deveres às famílias e às escolas. Nos dados recolhidos dos cadernos do Programa de Fortalecimento dos Conselhos Escolares, os direitos e os deveres referem-se às ações de execução de algo decretado. Cabe às famílias a execução, um lugar no qual a pluralidade, a cooperação e o compartilhamento de ideias não é valorizado. Como defende Foucault (2012, p. 43), quando se refere às grandes estratégias de poder como o ato de governar e a elaboração dos documentos da política, “[...] não se sabe ao certo quem tem o poder, mas se sabe quem não o tem".

Enfim, a família é convocada, parece ter voz, mas pouco sabemos ainda o quanto e como são ouvidas de fato no processo de gestão democrática. No Caderno 9, temos uma exceção, a qual trata da Educação do Campo. Nesse Caderno, sugere-se que a família seja convocada para o ensino de técnicas da cultura agrícolas. Aqui encontra-se a valorização do conhecimento familiar no currículo escolar. O Caderno recomenda a participação da família inclusive no planejamento das atividades escolares, em uma preocupação com a educação coletiva das crianças. Essas informações são encontradas somente nesse Caderno, o que é instigante e nos levará a novas investigações.

\section{Referências}

ADRIÃO, T.; CAMARGO, R. B. de. A gestão democrática na Constituição Federal de 1988. In: OLIVEIRA, R. P. de; ADRIÃO, T. (Orgs.). Gestão, financiamento e direito à educação: análise da LDB e da Constituição Federal. São Paulo: Xamã, 2002. p. 69-78.

BALL, S. J. Educação Global S.A.: novas redes políticas e o imaginário neoliberal. Tradução Janete Bridon. Ponta Grossa: UEPG, 2014.

Performatividades e fabricações na economia educacional: rumo a uma sociedade performativa. Educação \& Realidade, Porto Alegre, v. 35, n. 2, p. 37-55, maio/ago. 2010.

Revista Devir Educação, Lavras, vol.5, n2., p.207-223 jul./dez., 2021. 
BELL, J. Como realizar um projecto de investigação: um guia para a pesquisa em Ciências Sociais e da Educação. Lisboa: Gradiva, 1997.

BONDIOLI, A.; SAVIO, D. Participação e qualidade em educação da infância: percursos de compartilhamento reflexivo em contextos educativos. Tradução Luiz Ernani Fritoli. Curitiba: UFPR, 2013.

BRASIL. Constituição (1988). Constituição da República Federativa do Brasil. Brasília, DF: Senado Federal, Centro Gráfico, 1988.

Lei № 9.394, de 20 de dezembro de 1996. Diário Oficial [da] República Federativa do Brasil, Poder Legislativo, Brasília, DF, 23 dez. 1996. Seção 1, n. 248, p. 27833-27841.

Portaria No 2.896, de 16 de setembro de 2004. Diário Oficial [da] República Federativa do Brasil, Poder Executivo, Brasília, DF, 19 set. 2004a. Seção 2, n. 180, p. 7.

Ministério da Educação. Secretaria de Educação Básica. Programa Nacional de Fortalecimento dos Conselhos Escolares. Conselhos Escolares: Uma estratégia de gestão democrática da educação pública. Novembro de 2004b. Disponível em: <http://portal.mec.gov.br/seb/arquivos/pdf/Consescol/ce_gen.pdf>. Acesso em: 24 fev. 2017.

Ministério da Educação. Secretaria de Educação Básica. Programa Nacional de Fortalecimento dos Conselhos Escolares. Conselho Escolar e a aprendizagem na escola. Novembro de 2004c. Disponível em: <http://portal.mec.gov.br/seb/arquivos/pdf/Consescol/ce_cad2.pdf>. Acesso em: 24 fev. 2017.

Ministério da Educação. Secretaria de Educação Básica. Programa Nacional de Fortalecimento dos Conselhos Escolares. Conselho Escolar, gestão democrática e escolha do diretor. Novembro de 2004d. Disponível em: <http://portal.mec.gov.br/seb/arquivos/pdf/Consescol/ce_cad5.pdf>. Acesso em: 24 fev. 2017.

. Ministério da Educação. Secretaria de Educação Básica. Programa Nacional de Fortalecimento dos Conselhos Escolares. Conselhos Escolares: democratização da escola e construção da cidadania. Novembro de 2004e. Disponível em:

<http://portal.mec.gov.br/seb/arquivos/pdf/Consescol/ce_cad1.pdf〉. Acesso em: 24 fev. 2017.

. Ministério da Educação. Secretaria de Educação Básica. Programa Nacional de Fortalecimento dos Conselhos Escolares. Conselhos escolares. 2016. Disponível em: <http://portal.mec.gov.br/programa-nacional-de-fortalecimento-dos-conselhos-escolares>. Acesso em: 5 mar. 2017.

CAMPOS, M. M.; HADDAD, S. O direito humano à educação escolar pública de qualidade. Centre for Brazilian Studies, University of Oxford, Working paper, 2005. Disponível em: <http//:www.brasil.ox.ac.uk/workingpapers/Sergio\%20Haddad\%2092.pdf>. Acesso em: 9 fev. 2010.

CURY, C. R. J. O Conselho Nacional de Educação e a gestão democrática. In: OLIVEIRA, D. A. (Org.). Gestão democrática da educação: desafios contemporâneos. 8. ed. Petrópolis, RJ: Vozes, 2008. p.199-206.

DOURADO, L. F.; OLIVEIRA, J. F. de. A qualidade da educação: perspectivas e desafios. Cadernos Cedes, Campinas, v. 29, n. 78, p. 201-215, maio/ago. 2009. 
FERRAROTTO, L.; MALAVASI, M. M. S. A relação família-escola como alvo das atuais políticas públicas educacionais: uma discussão necessária. Educação: Teoria e Prática, Rio Claro, v. 26, n. 52, p. 232-246, ago. 2016.

FLORES, J. G. Análisis de datos cualitativos - Aplicaciones a la investigación educativa. Barcelona: PPU, 1994.

FOUCAULT, M. Hermenêutica do sujeito. 3 ed. São Paulo: Martins Fontes, 2010. . Não ao sexo rei. In: MACHADO, R. (Org.). Microfísica do poder. 2. ed. Rio de

Janeiro: Paz e Terra, 2015.

. Estratégia, Poder-Saber. In: MOTTA, Manoel Barros da. (Org.). Tradução Vera Lucia Avellar Ribeiro. Ditos e escritos, volume IV: Estratégia, Poder-Saber. Rio de Janeiro: Forense Universitária, 2012.

GHEDIN, E.; FRANCO, M. A. S. Questões de método na construção da pesquisa em educação. São Paulo: Cortez, 2008.

LAHIRE, B. O sucesso escolar nos meios populares: as razões do improvável. São Paulo: Ática, 1997.

MOSS, P. Para além do problema com qualidade. In: MACHADO, M. L. (Org.). Encontros e desencontros em educação infantil. São Paulo: Cortez, 2002. p. 17-25.

MURANAKA, M. A. S.; MINTO, C. A. Organização da educação escolar. In: MINTO, C. A. (Org.). Gestão, financiamento e direito à educação. 2. ed. São Paulo: Xamã; 2001. p. 45-68.

NOGUEIRA, M. A. Família e escola na contemporaneidade: os meandros de uma relação. In: REUNIÃO ANUAL ANPED, 28., 2005, Caxambu (MG). Anais eletrônicos... Caxambu: Centro de Convenções, 2005. Disponível em:

<http://28reuniao.anped.org.br/textos/gt14/gt14214int.rtf>. Acesso em: 6 jun. 2009.

PARO, V. H. O conselho de escola na democratização da gestão escolar. In:

Escritos sobre educação. São Paulo: Xamã, 2006. p. 79-89.

RESENDE, T. de F.; SILVA, G. F. A relação família-escola na legislação educacional brasileira (1988-2014). Ensaio: Avaliação e Políticas Públicas em Educação, Rio de Janeiro, v. 24, n. 90, p. 30-58, jan./mar. 2016.

SARACENO, C.; NALDINI, M. Sociologia da família. Lisboa: Estampa, 2003.

SILVA, P. Escola-família, uma relação armadilhada - Interculturalidade e relações de poder. Porto: Afrontamento, 2003.

Recebido em: setembro/2021.

Aprovado em: Novembro/2021. 